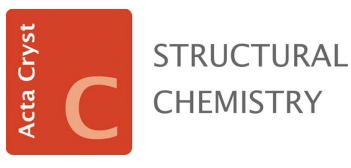

ISSN 2053-2296

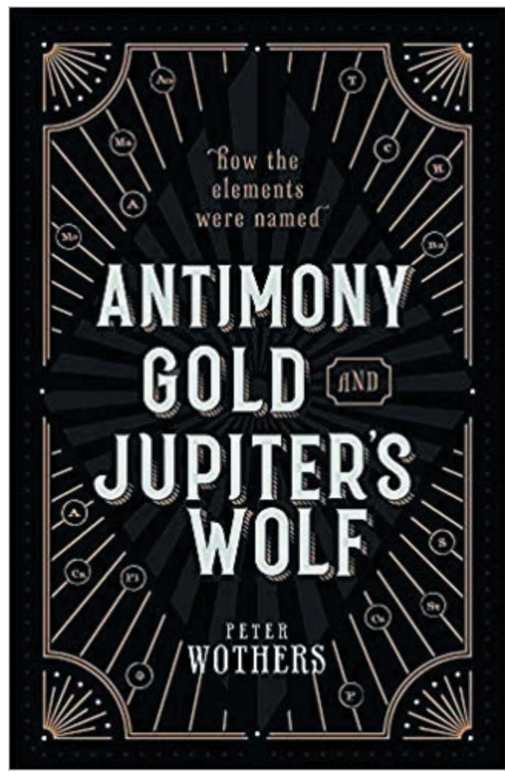

(C) 2020 International Union of Crystallography

\section{Antimony, Gold and Jupiter's Wolf. By Peter Wothers. Oxford University Press, 2019. Hardback, 273 pp. Price GBP 20.00, USD 25.95. ISBN 9780199652723.}

\author{
David Rickard*
}

School of Earth and Ocean Sciences, Cardiff University, Wales. *Correspondence e-mail: rickard@cardiff.ac.uk

Peter Wothers has added to his popular chemistry books with James Keeler (Keeler \& Wothers, 2003, 2013) with this solo effort about the discovery of the elements. This volume appears to fill a hole between the classical account by Weeks (1968), which is now freely available, recent selective accounts, such as Browne (2013) (which looks at Fe, C, $\mathrm{Au}, \mathrm{Ag}, \mathrm{U}, \mathrm{Ti}$ and Si) and Scerri (2013) (which looks at Pa, Hf, Re, Tc, Fr, At and Pm), and the short accounts in standard inorganic chemistry textbooks, such as Greenwood \& Earnshaw (1997). It was published appropriately in 2019, since it provides a background to the 150th anniversary of the publication Mendeleev's Periodic Table and the UNESCO International Year of the Periodic Table of Chemical Elements.

The book is 273 pages long and is divided into nine chapters. The 48 illustrations are mainly line drawings and half-tones and the general presentation is up to the high standard expected from Oxford University Press (OUP). The title has little to do with the contents of the book and refers to just antimony, gold and 'Jupiter's Wolf', which was a poetic term for wolfram briefly used by Henckel in 1747, and, in fact, $\mathrm{Sb}$, Au and W occupy very few of the 273 pages. As can be seen in Table 1 , most of the elements are discussed in Wothers's work although there are some notable absentees, like carbon and lithium.

The main elements in the chapters are indicated in bold in Table 1 and minor references are given in plain text. As you can see, there is very little order in the elements discussed in the chapters and the grouping starts historically with chapters 1 and 2, and then gradually descends into chemical Groups. It appears that the major elements selected are those that Wothers felt could tell a good story.

Wothers states that his purpose is to describe where the names of the elements come from and he refers specifically to how they were discovered rather than their etymology per se. In fact, the reader interested in the etymology of the names of the elements is better served by Peter van der Krogt's remarkable website Elementymology \& Elements Multidict (https://elements.vanderkrogt.net/index.php), which covers far more ground internationally and linguistically than Wother's book.

The first chapter examines the original seven metallic elements and discusses their astronomical relationships. Of course, there is actually little data available about the original discovery of these elements by the ancients. Wothers states (p. 1) 'We can't properly understand why some of the more recent elements were named as they were without first understanding these earlier historical connections'. So some etymology might have been useful here. For example, iron is derived from the Proto-Germanic isarnan meaning strong metal. Some reference to the effect of the introduction of iron weapons might have helped explain why iron was associated with Mars, the god of war. Some comment on the origin of the Latin root ferrum, which is far more important to chemists, might have illuminated my ignorance, and a discussion of why this caught on for chemistry would have been interesting. The etymology is addressed more directly in the following chapters.

The second chapter follows the historical thread and discusses the metallic and submetallic elements, such as $\mathrm{Sb}, \mathrm{As}, \mathrm{Bi}, \mathrm{Co}$ and $\mathrm{Ni}$, which rather torpedoed the medieval European idea of their being just seven elements and these being connected to the seven bodies of the solar system known at the time. Interestingly, one planet was consistently missed out of these speculations and appears much later in the story (i.e. the Earth; tellurium was named by the German chemist Klaproth in 1801). 
Table 1

The main elements in the chapters.

\begin{tabular}{|c|c|c|c|}
\hline Chapter & Title & Pages & Elements \\
\hline 1 & Heavenly Bodies & 31 & $\begin{array}{l}\text { Au, Ag, Fe, Hg, Sn, Cu, Pb, U, } \\
\text { Ra, Po, Np, Bk, Cf, Am, Og, } \\
\text { Sg, Fr, Se, Te }\end{array}$ \\
\hline 2 & Goblins and Demons & 27 & Bi, Sb, As, Co Ni, Zn, Cd \\
\hline 3 & Fire and Brimstone & 23 & $\mathbf{S}, \mathbf{P}$ \\
\hline 4 & $H$ Two $O$ to $O$ Two $H$ & 41 & $\mathbf{H}, \mathbf{O}, \mathbf{N}$ \\
\hline 5 & Of Ashes and Alkalis & 31 & $\mathrm{Na}, \mathbf{K}, \mathrm{Ca}, \mathrm{Mg}, \mathrm{Ba}$ \\
\hline 6 & Loadstones and Earths & 28 & $\begin{array}{l}\text { Si, Mn, Ba, W, Mo, Al, Zr, Sr, } \\
\text { Be }\end{array}$ \\
\hline r & The Salt Makers & 15 & $\mathbf{C l}, \mathbf{B r}, \mathbf{I}, \mathbf{F}$ \\
\hline 8 & From Under the Nose & 29 & $\begin{array}{l}\text { He, Ar, Kr, Ne, Xe, Cs, Rb, Th, } \\
\text { In, Ga, Sc, Ge, Y, Yb, Er, } \\
\text { Tb, Tu, Ho, Ge }\end{array}$ \\
\hline 9 & Unstable Endings & 4 & Po, Ra, Rd, At, Nh, Ts, Og \\
\hline
\end{tabular}

Sulfur and phosphorus have a chapter more-or-less to themselves and this is followed by a chapter containing a detailed account of how it was determined that air consisted of several gases and was not just a single compound. The chapter title, $H$ Two $O$ to $O$ Two $H$, reflects Lavoisier's fundamental mistake in naming hydrogen and oxygen; Wothers points out that, in reality, they have exactly the opposite attributes to those which the etymology of their appellations suggests. In this chapter, Wothers covers the discovery of hydrogen and oxygen and includes a delightfully sympathetic account of the phlogiston and caloric theories.

The discoveries of the alkali metals are treated in chapter 5. The chapter is very Eurocentric and, although alkali itself is a direct Arabic loan word, all the descriptions and illustrations are European and there are no references to the original works of the great Arab chemists of the Middle Ages. As is a common theme of this book, this chapter is a bit of a pot pourri since Wothers also includes an account of the origins of the chemical symbols.

Chapter 6 is also an interesting hotchpotch. Here Wothers considers the origins of the alkali earth metals, as well as magnetism, and manganese, tungsten, graphite and aluminium. I might take exception to the Swedish for tungsten being represented consistently as 'tungste' (pp. 171 and 173) and perhaps Berzelius being introduced as the last of a long list of Swedish chemists (p. 157), but these are minor quibbles.

Chapter 7, The Salt Makers (15 pp.), is a short chapter dealing with the halogens, but ending with 17 lines on
Mendeleev's Periodic Table (together with a two-thirds page facsimile of the original, courtesy of the Master and Fellows of St Catherine's). I learned that nitric, sulfuric and hydrochloric acids are called mineral acids because they can all be obtained by heating combinations of minerals (p. 180). As usual the discussion is mainly limited to western European contributions.

Chapter 8 more-or-less ditches the historical theme entirely and reverts to classical chemistry systematics looking at the final Group of the Periodic Table. As usual in this gallimaufry, the chapter briefly mentions the rare earth elements on its way to discussing in some detail the isolation and identification of the noble gases.

The final chapter, Unstable Endings, is just four pages long and very briefly considers uranium, thorium and radium before even more briefly mentioning the transuranic and superheavy elements.

I am unsure who the book is aimed at. It is presented as a book for the general public but the level of presentation is extremely variable. Wothers has amassed a personal collection of early works on the history of chemistry and he has used these extensively to illustrate the present text. But consequent swathes of cited text interrupt the flow and the book is not a good read; rather it is a book to dip into during quiet moments. The book is very Eurocentric and features esoteric western European publications from the 17th and 18th centuries where, I suppose, the heart of Wother's personal collection lies. On the other hand, I learned (or was reminded of) a lot from reading it and the journeys down the highways and byways of early chemistry were often entertaining.

\section{References}

Browne, J. (2013). Seven Elements That Have Changed the World: Iron, Carbon, Gold, Silver, Uranium, Titanium, Silicon. London: Weidenfeld \& Nicolson.

Greenwood, N. N. \& Earnshaw, A. (1997). Chemistry of the Elements, 2nd ed. Oxford: Butterworth-Heinemann.

Keeler, J. \& Wothers, P. (2003). Why Chemical Reactions Happen. Oxford University Press.

Keeler, J. \& Wothers, P. (2013). Chemical Structure and Reactivity: An Integrated Approach, 2nd ed. Oxford University Press.

Scerri, E. R. (2013). A Tale of Seven Elements. Oxford University Press.

Weeks, M. E. (1968). The Discovery of the Elements, 7th ed., revised and with new material added by Henry M. Leicester. Easton: Journal of Chemical Education. 